\title{
Performance of drop shaped pin fin heat exchanger with four different fin dimensions
}

\author{
A.A. Mohamed ${ }^{1}$ and $O$. Younis $2,3,{ }^{*}$ \\ ${ }^{1}$ Mechanical Engineering Department, Faculty of Engineering and Technology, Nile Valley University, Atbara, Sudan \\ ${ }_{2}$ Mechanical Engineering Department, College of Engineering at Wadi Addwaser, Prince Sattam Bin Abdulaziz University, KSA \\ ${ }^{3}$ Mechanical Engineering Department, Faculty of Engineering, University of Khartoum, Sudan
}

\begin{abstract}
In engineering, there are two primary heat transfer procedures of fluids namely, heating and cooling within a conduit that are well recognized. The heat transfer literacy remains a core component to design the heat exchangers. The study aims to present the consequences of drop shaped pin fin hear exchanger performance with four different fin dimensions. A rectangular duct with different drop-shaped pin fins dimensions is present in the heat exchanger, having similar heat transfer wetted surface area. ANSYS FLUENT 14.5 conducted three-dimensional finite volume to select the optimum pin fin dimension. The numerical results for the four cases L/D 1 , $1.25,1.5$ and 1.75 indicated heat transfer had no effect on the variations in pin tail length; however, it affected frictional losses or pressure drop. There is significant decrease in the frictional loss as the result of increase in the pin tail length. The pun fin drop showed significant decrease in friction power, unlike the round pins. The ratio of pin height to the cylindrical portion of the pin (H/D) had major impact on the wetted surface area, which affects the rate of heat transfer.
\end{abstract}

ARTICLE HISTORY

Revised: $30^{\text {th }}$ Jan 2020

Accepted: $4^{\text {th }}$ Feb 2020

\section{KEYWORDS}

Compact heat exchanger; heat transfer;

pressure drop;

pin fins;

turbulent flow.

\section{INTRODUCTION}

Heating and cooling of the fluid in conduits is considered among the most significant heat transfer procedures. Design and analysis of the heat exchangers between fluid and conduit wall is important to gain knowledge about the heat transfer coefficient. Moreover, the sizes, pre-heaters, super-heaters, and boilers between the fluid and inner surface of tubes help in the assessment of heat transfer coefficient. It is necessary to evaluate heat transfer coefficients for fluids flowing inside ducts, in the design of air-conditioning and refrigeration equipment [1]. Increased surface density and smaller flow channels are achieved through escalating demand for heat exchangers compactness in various refrigeration and airconditioning applications within the automotive industry. The efficient heat transfer from one medium to another is possible through a heat exchanger [2,3]. They play an important role in different applications, specifically refrigerators, air conditioning systems, and generating power [4]. With regard to heat transfer, energy saving is the main concern, which can be resolved by increasing the performance of heat exchangers [5]. The large heat transfer surfaces are responsible for the characterization of compact heat exchangers, without concerning the shell and tube exchangers. These components tend to enhance the process design, processing conditions, plant layout, cost and reduced space, and energy requirements [6].

Active, passive and compound improvement methods are classified within the heat transfer improvement methods. External power provides base for active heat transfer improvement method that enables generation of electrostatic fields, rotation of heat transfer surfaces, mixing of working fluids, and vibration of heat transfer surfaces. The enhancement of active heat transfer is directly linked with vibration and acoustic noise. The heat transfer improvement techniques are present within the heat transfer improvement elements. The passive techniques along with the heat transfer surface area help in achieving higher values of the heat transfer coefficient product [6]. Surface or geometrical changes are used by these techniques to flow the channel by implementing additional devices or inserts. Therefore, there is no need of direct input of external power for these techniques. On the contrary, a system is used for increasing the fluid pressure drop in these techniques [7]. In this regard, compound enhancement is termed as a system where two or more techniques are joined to produce heat transfer for improvements [7].

The incorporation of heat transfer surface within the system with $\beta$ greater than about $700 \mathrm{~m} 2 / \mathrm{m} 3$ or a hydraulic diameter $D h \leq 6 \mathrm{~mm}$ labels compact heat exchanger as gas-to-fluid exchanger. The use of compact heat exchanger helps in operating a gas or a liquid stream. However, a typical process industry shell is incorporated with $2 / 3^{\text {rd }}$ greater than high-fin density low finned on one hand; whereas, a surface density of less than $100 \mathrm{~m} 2 / \mathrm{m} 3$ on other hand. A typical plate heat exchanger comprises of fluid side or the average overall heat transfer coefficient. However, the bulk and mass of fluid does not characterize the presence of heat exchanger. If a high surface area and density is not incorporated, then it would be more massive and bulkier [8]. Compact Heat Exchanger is a subject of immense study in the engineering applications since it plays an essential role in these equipment's for improving their performance. In such applications, an enclosed pin fin heat exchanger duct with round cross-section pins is the most common design.

Heat transfer and pressure drop characteristics improve through the drop shaped pin fins, unlike the circular pin fins that are used for transfer of same heat on the wetted surface area [9-13]. Therefore, single-phase forced convection 
enhancement techniques are focused in this study that minimizes the pressure drop across the heat exchanger and maximizes the heat transfer. There is enhancement in convective heat transfer as demonstrated by various techniques developed during the last few decades. The straight elliptical pin fin present under fully developed laminar flow conditions is the best fin geometry considering the overall performance point of view [14]. The impact of pin fin spacing and material on the performance of fin heat exchanger was investigated by Dewan et al. [14]. According to Bergelin et al. [15] the flow ranging between 200 - $5000 \mathrm{Re}$ is known as transition regime; however, if below 200 then it is known as laminar. The pressure drop characteristics of diamond shaped pin fin arrays was investigated by Sparrow et al. [16]. These results were applicable on space shuttle as it facilitates design applications through compact algebraic formulas.

The numerical stimulation of heat sink using the $\mathrm{k}-\varepsilon$ turbulence model was conducted by Yang et al. [17]. The sink was presented with fins of non-uniform height, along with a confined impingement cooling. The main aim of the study was to examine the impact of heat sink on thermal performance. Re of 12 non-uniform fin height designs ranging between 15,000 to 25,000 were considered, which showed that increase in the fin height near the center of heat sink reduces the junction temperature [14]. Another study examined the corresponding pressure drop over a flat surface with circular cross section perforated pin fins in a rectangular channel by enhancing the heat transfer. The cross-section area of rectangular channel was $100-250 \mathrm{~mm}^{2}$. The optimum design parameters were obtained using the Taguchi experimental design method. The results showed that heat transfer is enhanced by using circular cross section pin fins, where the optimum condition was Re number 42,000, streamwise distance between fins to be $51 \mathrm{~mm}$, and fin height of $50 \mathrm{~mm}$. A detailed investigation of heat transfer enhancement from dimpled fins was conducted by Elyyan et al. [18] using large eddy and numerical simulations over a wide range of Reynolds number that cover laminar, turbulent, and transitional flow regimes. Two cases were considered, where case 1 had undergone transition at $900 \mathrm{Re}$; while, case 2 developed flow instabilities at $450 \mathrm{Re}$ with smaller fin pitch configuration. The results showed that heat transfer augmentation on the dimple side is contributed by generating vorticity within the dimple cavity and rim. Whereas, the protrusion side is contributed by flow impingement and acceleration between protrusions.

The investigation of enhanced wall heat transfer and loss of total pressure characteristics for two alternative elliptical pin fin arrays was conducted by Uzol et al. [19]. The comparison of results with conventional circular pin fin arrays showed that overall performance of elliptical pin fin array for good. Five different turbulence models for pin fin heat sinks were compared by Moshfegh and Nyiredy [20]. The results demonstrated that there is significant impact of choosing the right turbulence model and near-wall treatments on the pressure drop and coefficient of heat transfer. Pin fin heat sinks with circular, elliptic, and square cross sections were experimented for staggered and inline arrangement by Yang et al. [21]. There was increase in the heat transfer coefficient for staggered arrangement with a rise of fin density considering all the three configurations. The lowest pressure drop was exhibited by elliptic pin fin and it also had smallest thermal resistance for staggered arrangement bar fixed pumping power. The fully developed flow over tube banks is the one having more than 16 rows.

The numerical results with experimental data for circulate pin fin heat exchanger were compared by Dewan et al. [22] using the RNG k- $\varepsilon$ turbulence model having standard wall functions. The results showed that there is significant impact of choosing the appropriate turbulence model and near-wall treatment on the fluid dynamics and thermal behavior of heat exchanger. Another study considered the three-dimensional array of rectangular perforated fins with square windows arrangement on lateral surface of fins and fluid flow to examine the conjugate conduction-convection heat transfer. For this purpose, Navier-Stokes equations and RNG k- $\varepsilon$ model were used, which showed that unlike solid fins, the perforated fins possess considerable reduction in weight and increased total heat transfer.

The gas turbine cooling, electronics cooling, and other applications possess large area density for extensive heat flux removal rates. However, there is limited attention received for other pin fin shapes. There is decrease in the heat transfer and total pressure across the heat exchanger and over the fin if round pin fins are used in its early flow separation. However, the use of different pin shapes might stop the flow separation for enhancing the performance of heat exchangers. It is not practical to conduct a thorough experimental attribution of different probable shapes because it is costly and time consuming. The increased cost is because of the increased costs of experimental tools and parts. Therefore, a new model is required for different configurations that decreases the geometric flexibility of the existing testing models. The geometrical flexibility can be remedied by providing a rapid and cost-effective approach to have a greater flexibility in the boundary conditions and geometry. Different pin shapes and arrangements and configurations can be examined by including Reynolds numbers and turbulence levels. The forecasted performance of heat exchanger design was validated through experiment after the selection of an optimum heat exchanger design.

The heat exchangers are subject of interest in extensive engineering application because of their important functions. Cooling electronic components is one of the most important new applications for increasing the life expectancy and functioning efficiently. Moreover, the engines operating at high turbine inlet temperature include the modern highperformance has turbine engines. Efficiency and performance increase the inlet temperature, which is restricted to withstand the metal temperature for these types of engines. The cooling process of the hot gas flow is required within the engine components exposed specifically at the gas turbine blades leading edge. The critical location demands enforced structure of the blade. The engine compressor supplies internal cooling air for each blade to increase the cycle efficiency. Therefore, a high efficiency heat exchanger with small pressure drop and high heat transfer are included within the design problem. The problems arising in a design can be overcome by a small shroud enclosed ducted heat exchanger with staggered pin fins arrays and air in cross flow over the pins. The progress of advanced software and computers is possible through numerical modeling. One of the advantages of using numerical modeling is its cost and time effectiveness with appropriate boundary and geometry conditions. 
The study aims to investigate one of the active heat transfer enhancement devices for the heat exchanger. This study has focused entirely on the single-phased forced convection improvement methods. The study aims to build threedimensional numerical model that comprises of rectangular duct with staggered arrays of drop-shaped pin fins in a cross flow of air. The study has also investigated the stream wise and span wise spacing impacts along with pin tail elongation. The overall heat exchanger performance has been measured based on the pin shape and optimum geometric configuration. Comparison between heat transfer and pressure drop for drop shaped pins and round pins CHE is conducted in this study. Moreover, the accuracy of numerical work in the experimental section was evaluated through the empirical data. The study results would be significant as they would help in designing different heat exchangers, especially concerned with the electronic components. It can be stated that present study aims to:

- To simulate the heat exchanger of the different drop shaped fin dimension having same wetted surface area for different Reynolds number in the range of 5000 to 20000, to avoid numerical complications, with interval of 2500 .

- To compare the performance of the different cases for selecting optimum drop shaped fin dimension based on minimum pressure drop and maximum heat transfer.

\section{NUMERICAL MODELLING}

In the case of two-dimensional turbulent flow, it is assumed that the flow is steady in mean and incompressible governing time. Velocity, mean fluid temperature, and mean pressure are the main variables associated with the equation of governing energy to obtain the temperature field. In the present scenario, the turbulence and the corresponding transport equations for turbulence kinetic energy and rate of dissipation are treated with the RNG k- $\varepsilon$ turbulence model. The computations with the experimental data of Kays for drop shaped pin fin were compared by validating the computational model. The comparison of various pin fin cross sections is important due to modelling of the manufactured pin configuration under complex turbulent flow.

The pin fin section, entrance section, and exit section are considered as the important channels to relate to the CHE domain. The pin fin section involves eight rows of in-line pin fins, along with the axes perpendicular with the flow. There is significant difference in pin shapes of cylindrical, rectangular and drop-shaped shapes among the pin-fin section. The domain comprising of 10 staggered shaped cross-pin rows is presented in Figure 1. The major geometrical dimensions are classified into;

- $\quad$ span-wise pin spacing (S)

- $\quad$ diameter of the cylindrical portion of the pin (D)

- $\quad$ pin-tail length $(\mathrm{L})$

- $\quad$ stream-wise pin spacing $(\mathrm{X})$

- $\quad$ pin height $(\mathrm{H})$

The stream-wise pin spacing and the span-wise pin spacing were emphasized through constant vales at $50 \mathrm{~mm}$. The bank of 45 solid pins spanning at the end walls comprises of $550 \mathrm{~mm}$ as length, $250 \mathrm{~mm}$ as width and $(\mathrm{H})$ as height together. The fluid and solid materials considered in this study comprised of rectangular box minus the drop shaped pin fins. The solid pin material chosen for this study was aluminum with thermal conductivity of $202.4 \mathrm{~W} / \mathrm{m}-\mathrm{k}$. Air was chosen as the fluid for this study with following thermo-physical properties;

- $\rho=1.225 \mathrm{~kg} / \mathrm{m}^{-3}$

- $\mu+1.789 \times 10^{-5} \mathrm{~kg} / \mathrm{ms}^{-1}$

- $\operatorname{Pr}+0.71$

- $\mathrm{C}_{\mathrm{p}}=1006.43 \mathrm{Jkg}^{-1} \mathrm{~K}^{-1}$

Previously, researches have focused on circular pin fins possibly due to their efficiency and easiness to construct. In contrast, it is not apparent that either lowest pressure drops or highest heat transfer comprises within the circular pin fins. Unlike the circular cylinders, the cylinders with elliptic cross-section are presented with decreased resistance to flow and low friction factor. These cylinders also include higher surface wetted area that can augment the heat transfer.

Selection of drop shaped pin fin results in improvement of the heat transfer and pressure loss. A circular leading edge extending the triangular trailing edge based on $90+\times 2 \alpha$ degree was comprised within the cross-section. The circular arc was tangent by the triangle edges. L refers to the distance between the triangle apex and the center of the circle. The increase in the wetted surface area of heat exchanger was possible by increasing the triangular portion of the pin that increases the efficiency and heat transfer. Moreover, major decrease in the pressure loss win the circular cross-section occurs due to decrease in flow resistance and friction factor because of separation.

All the pin fins were equal to the total pin fin area. Rectangular duct with 40D length, 10D height, and 10D length is required at entrance section of the heat exchanger. The next section comprises of similar characteristics. The comprehensive establishment of laminar flow condition at the entrance was assured by constructing front of the heat exchanger pin-fin section. An adiabatic element has been comprised within the entrance and exit duct. The sensitivity of different parameters on mesh quality is presented in the constructed model. 

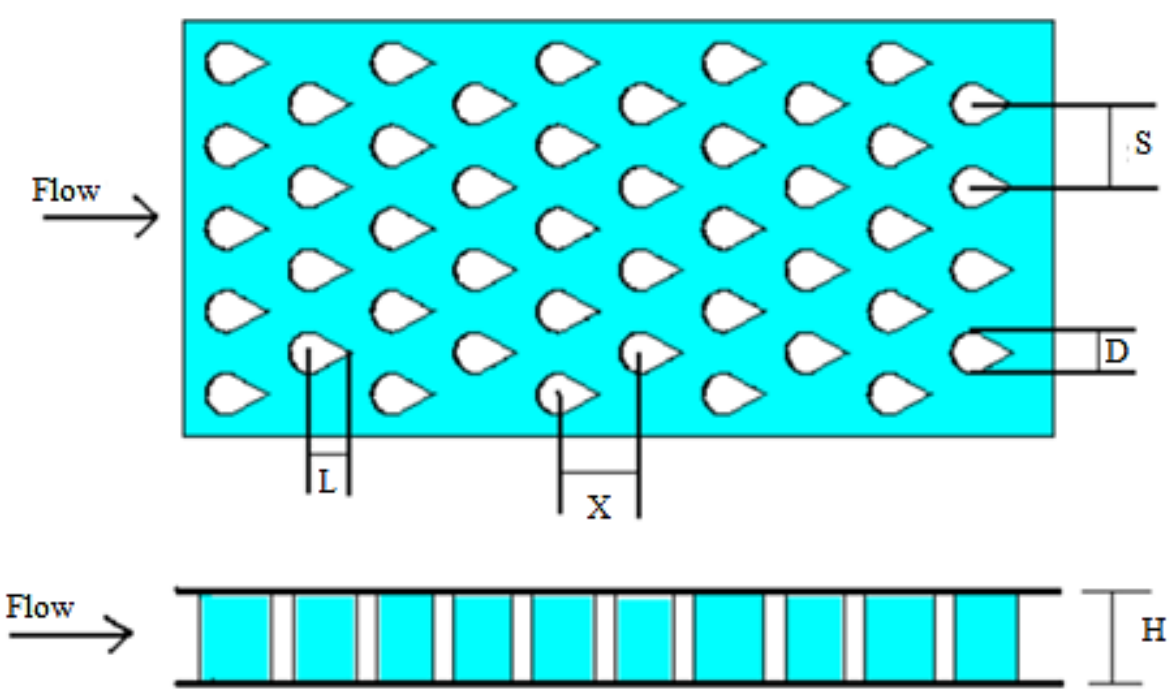

Figure 1. Pin fin section in the computational domain.

\section{Geometry and Computational Domain}

Four drop shaped pin fin geometries having typical heat transfer wetted surface area were studied (Table 1). The stream-wise pin spacing (X), span-wise pin spacing (S), and ratio of pin height to the cylindrical portion of the pin (H/D) remained constant in all the models, at the unity to be a short fin. While, there were certain variation in other geometrical dimensions (H, L, and D).

Table 1. Geometrical dimension of the tested cases.

\begin{tabular}{cccccccccc}
\hline Cases & $\mathrm{H} / \mathrm{D}$ & $\mathrm{L} / \mathrm{D}$ & $\begin{array}{c}\mathrm{D} \\
(\mathrm{mm})\end{array}$ & $\begin{array}{c}\mathrm{L} \\
(\mathrm{mm})\end{array}$ & $\begin{array}{c}A_{w f} \\
\left(\mathrm{~mm}^{2}\right)\end{array}$ & $\begin{array}{c}A_{w h} \\
\left(\mathrm{~mm}^{2}\right)\end{array}$ & $\begin{array}{c}V_{o p} \\
\left(\mathrm{~mm}^{3}\right)\end{array}$ & $\begin{array}{c}D_{h} \\
(\mathrm{~mm})\end{array}$ & $\begin{array}{c}A_{\text {ave }} \\
\left(\mathrm{mm}^{2}\right)\end{array}$ \\
\hline 1 & 1 & 1.75 & 31.55 & 55.22 & 426528.61 & 391819.3 & 2495611.48 & 23.40 & 4537.48 \\
2 & 1 & 1.5 & 33 & 50 & 428119.30 & 391819.3 & 2609981.56 & 24.39 & 4745.42 \\
3 & 1 & 1.25 & 34.85 & 43.57 & 430160.15 & 391819.3 & 2756719.37 & 25.63 & 5012.22 \\
4 & 1 & 1 & 36.84 & 36.84 & 432338.50 & 391819.3 & 2913343.93 & 26.95 & 5296.99 \\
\hline
\end{tabular}

\section{Mathematical Description}

ANSYS Fluent 14.5 is used to solve two-dimensional Navier-Stokes equations using CFD predictions. Two dimensional, steady and turbulence are classified within the computational model. One-fourth of the heat exchanger was systemized and reduced by the computational requirements and time as the advantages of symmetry planes in heat exchanger are considered. Fluid pressure and velocity were coupled using SIMPLE algorithm. QUICK was set with kinetic energy, turbulence, turbulence dissipation rate, discretization of momentum, and energy equations. The residual for converged solution of continuity, component of velocity, turbulence kinetic energy and turbulence dissipation rate are below $10^{-3}$; while, for energy it is below $10^{-6}$ [23-26]. It is important to specify uniform hexahedral element meshing to cover the entire model volume. Similarly, the present study has conducted computations using realizable $k-\varepsilon$ model, (under the two -equation model category), which uses substantial enhancements as the flow features entail strong streamline rotation, vortices, and curvature [27-29].

Realizable $k-\varepsilon$ model, (under the two -equation model category) was used to carry out the computations. The Realizable $\mathrm{k}-\varepsilon$ model, which is a relative new turbulence model is the last member of $\mathrm{k}-\varepsilon$ family. They differ in two major ways [26];

- $\quad$ Formulation of turbulent viscosity

- New transport equation for dissipation rate

The output of the ANSYS CFD/Flotran was reported from the mass flow, pressure drop, the outlet bulk temperature, and the total heat transfer rate; while, the other parameters are computed as shown below. Equation (8) and (9) provide the transport equations for both the kinetic energy and the dissipation rate, respectively. 


$$
\begin{gathered}
U_{j} \frac{\partial}{\partial x_{j}}(\rho k)=\frac{\partial}{\partial x_{j}}\left(\left(\mu+\frac{\mu_{t}}{\sigma_{k}}\right) \frac{\partial k}{\partial x_{j}}\right)+G_{k}-\rho \varepsilon \\
U_{j} \frac{\partial}{\partial x_{j}}(\rho \varepsilon)=\frac{\partial}{\partial x_{j}}\left(\left(\mu+\frac{\mu_{t}}{\sigma_{\varepsilon}}\right) \frac{\partial \varepsilon}{\partial x_{j}}\right)+\rho C_{1} S_{\varepsilon}-\rho C_{2} \frac{\varepsilon^{2}}{k+\sqrt{v \varepsilon}}
\end{gathered}
$$

where,

$$
C_{1}=\max \left[0.43, \frac{\eta}{\eta+5}\right], \eta=S \frac{k}{\varepsilon}
$$

Like the other $\mathrm{k}-\varepsilon$ models, the turbulent viscosity is calculated using:

$$
\mu_{t}=\rho C_{\mu} \frac{k^{2}}{\varepsilon}
$$

The only difference is the constant $C_{\mu}$

The closure coefficient;

$$
C_{2}=1.9, \sigma_{k}=1, \sigma_{\varepsilon}=1.2
$$

The presence of strong streamline curvature, rotation, and vortices improved the Realizable $\mathrm{k}-\varepsilon$ model over the standard $\mathrm{k}-\varepsilon$ model [26]. The performance of the different models was compared using average heat transfer coefficient, friction coefficient, and average Nusselt number. The average array heat transfer coefficient, provided by the heat transfer summary in the output file of FLUENT at the end of the simulation is calculated using thermal energy difference between the flow inlet and the outlet. The summary of heat transfer was calculated owing the log mean temperature difference as below:

$$
\bar{h}=\frac{\Delta Q}{A_{w h} \Delta T_{l m}}
$$

where, $A_{w h}$ is the heat transfer wetted surface area.

$$
\Delta T_{l m}=\frac{\left(T_{\text {wall }}-T_{\text {in }}\right)-\left(T_{\text {wall }}-T_{\text {out }}\right)}{\ln \frac{\left(T_{\text {wall }}-T_{\text {in }}\right)}{\left(T_{\text {wall }}-T_{\text {out }}\right)}}
$$

The inlet bulk fluid temperature islet constant at $300 \mathrm{~K}$, while calculating the outlet bulk fluid temperature through the FLUENT program. Nusselt number provides ratio of convective heat transfer over a surface that occurs by fluid motion to the corresponding conductive heat transfer to measure the ability of heat transfer. In the present study, the Nusselt number is given by the following relation:

$$
N_{u}=\frac{\bar{h} D_{h}}{k}
$$

The dimensionless friction factor that was used was defined as follows:

$$
f=\frac{\Delta P_{a v e} D_{h}}{\frac{1}{2} \rho \bar{U}^{2} L}
$$

where, $\Delta P_{\text {ave }}$ is the average pressure difference between the inlet and outlet sections of the heat exchanger, $\mathrm{L}$ is the total stream-wise length of the array.

The wetted surface area, interacting with the coolant fluid, is demonstrated as the total heat exchanger surface. The upper and lower fluids on the wetted surface area interact with the pin areas. 
Flow Wetted Surface Area

$$
A_{w f}=2\left[L W+L H-N_{p}\left(\frac{\pi D^{2}}{4}\left(\frac{\pi+2 \theta}{2 \pi}\right)+\frac{D}{2} l \cos \theta\right)\right]+N_{p} H\left[\frac{D}{2}(\pi+2 \theta)+2 l \cos \theta\right]
$$

Heat Transfer Wetted Surface Area

$$
A_{w h}=2\left[L W-N_{p}\left(\frac{\pi D^{2}}{4}\left(\frac{\pi+2 \theta}{2 \pi}\right)+\frac{D}{2} l \cos \theta\right)\right]+N_{p} H\left[\frac{D}{2}(\pi+2 \theta)+2 l \cos \theta\right]
$$

\section{Open Volume}

The total fluid volume inside the heat exchanger defines the total volume. The volume occupied by the pins reduces due to open volume that is like the total heat exchanger internal volume.

$$
V_{o p}=L W H-N_{p} H\left[\left(\frac{\pi D^{2}}{4}\left(\frac{\pi+2 \theta}{2 \pi}\right)+\frac{D}{2} l \cos \theta\right)\right]
$$

\section{Hydraulic Diameter}

The ratio of total wetted surface area to the open duct volume accessible for flow is defined as the hydraulic diameter. This diameter provides authentic characteristic length for the heat exchanger to represent different configurations.

$$
D_{h}=\frac{4 V_{o p}}{A_{w f}}
$$

Average Flow Area

$$
A_{\text {ave }}=\frac{V_{o p}}{L}
$$

\section{Reynolds number}

Reynolds number is likely to be defined after calculating the hydraulic diameter and the average flow as:

$$
R e=\frac{\dot{m} D_{h}}{\mu A_{\text {ave }}}=\frac{\rho \bar{U} D_{h}}{\mu} ; \quad \bar{U}=\frac{\dot{m}}{\rho A_{\text {ave }}}
$$

\section{Outlet Temperature}

The energy balance across the ends of heat exchanger was used to calculate the outlet temperature. A difference of less than $0.1 \mathrm{~K}$ between the computed and numerical result validate the run.

$$
T_{\text {out }}=T_{\text {in }}+\frac{Q}{\dot{m} C_{p}}
$$

\section{Boundary Conditions}

The temperature distribution in the solid pins were computed as short pins and eliminated the high thermal conductivity. Thereby, with a unified temperature of $312 \mathrm{~K}$, these pins are presumed to be isothermal accordingly to the Summers [22] experimental data. It is considered isothermal with $306 \mathrm{~K}$ uniform temperature because it has high thermal conductivity to treat the pins as short. The no slip condition, where the end wall was treated with constant temperature of $306 \mathrm{~K}$ was applied with the pin surfaces. There was zero velocity in three directions $(U x=U y=U z=0)$ after the implementation of no slip condition because of the rigid boundary. In the three conditions, the exit end walls and inlet walls were modeled with zero velocity as adiabatic walls. The symmetry walls were sown as adiabatic model because of zero heat flux. In $\mathrm{z}$ direction given for the mid-height plane, the mid-width plane was provided a zero velocity in the $y$ direction and zero velocity. This allows construction of a velocity profile but prevents the flow of pin fins from crossing the boundary. Same features are presented in the exit and inlet symmetry within the test section. Temperature was kept constant at $300 \mathrm{~K}$ for the inlet air temperature. The Reynolds number was selected for the inlet velocity, which was relied on the wetted surface area.

The pin surfaces were applied with no slip condition. Constant temperature of $312 \mathrm{~K}$ was maintained at the end wall. The application of no slip condition led to zero velocity in three directions since it is a rigid boundary $(U x=U y=U z=$ 
$0)$. In three directions, the entrance and exit walls were modelled as adiabatic walls with zero velocity $(U x=U y=U z$ $=0$ ). Here, the symmetry walls are assumed to be adiabatic and modelled with zero heat flux. The mid-height symmetry plane MHSP was given zero velocity in the $\mathrm{z}$ direction $(U z=0)$; while, the mid-width symmetry plane MWSP was given a zero velocity in the y direction $(U y=0)$. A velocity profile can be developed from the mid-height symmetry plane and prevent too the flow from boundary crossing. Comparatively, the exit and inlet symmetry walls have the similar aspects. With zero heat, the sidewall was modelled to be adiabatic. There was no application of the slip condition with zero velocity in the three directions $(U x=U y=U z=0)$. Likewise, similar properties are possessed by the test section comprises of the inlet and exit sidewalls. The fluid (incompressible ideal gas - air) was modelled for simplifying the model, with inlet air temperature set at $300 \mathrm{~K}$. The Reynolds number was chosen for the inlet velocity as relied on the wetted surface area.

\section{Inlet section}

Half inch-thick Plexiglas was used to design the inlet section to minimize friction. The dimensions characterizing development of total inlet section include;

- $\quad$ Reynolds number $=100,000$

- $\quad \mathrm{L}=9 \mathrm{ft}$ long

- $\mathrm{W}=7.5 \mathrm{D}$

- $\mathrm{D}=250 \mathrm{~mm}$.

\section{Test Section}

6061 T6 aluminum plate and rods were used to develop upper and lower plates, and the pins of the test section to achieve a high conductivity for the end walls and pins. Plexiglas was used for constructing the side walls. The test section with a length of $250 \mathrm{~mm}$, a height of $33 \mathrm{~mm}$, and a width of $50 \mathrm{~mm}$ helped to achieve 1.5-1.5-1.5 configuration with a pin diameter of $33 \mathrm{~mm}$. A total of 10 rows of staggered drop shaped cross-pins where executed with axes perpendicular to the flow direction Within HE. At each heater location, a thermocouple was placed for keeping the lower and upper plates at the uniform temperature.

\section{Exit Ducts}

Coordination was maintained in the exit section and circular cross-section of the exit flow straightening section for rectangular exit cross-section of the exit test section. Heat losses were reduced by the insulation of the exit section.

The implementation of pins was not ensured in any special boundary condition. There is two-sided wall for each pin, in which one side is solid region; while, other is the fluid one. The import of grid with this type of wall into fluent results in the construction of a shadow zone. However, name of shadow is likely to presented in the shadow face zone field in the wall panel. The coupled option under thermal conditions should be selected for coupling the two sides of the pin-fin. Heat transfer is directly computed from the solution in the adjacent cells by the solver; therefore, no additional thermal boundary conditions are required.

\section{Verification and Validation}

The computational fluid dynamics ensure the accuracy and reliability of computational stimulation. Validation is the preliminary mean for evaluating the accuracy and reliability in computational simulations. Benchmark experimental data has been used to validate the process that assess modelling uncertainty. The computation of CFD in a modular and rectangular wind tunnel was presented for empirical attribution of a staggered array pin fin compact heat exchanger. The drop shaped pin fin revealed the comprehensive analysis of the heat transfer and pressure drop behavior.

The experimental data and CFD prediction validated the numerical results for average heat transfer coefficient, friction coefficient, and Nusselt number curves. The results showed variation among these aspects. The first curve was measured through CFD simulation and the experimental data. Moreover, the numerical results and experimental data curves helped in observing typical trends.

\section{Meshing and Mesh Independency Test}

The primary means to assess the reliability and accuracy of computational simulations is defined as verification. There are two aspects of verification assessment; firstly, it shows no programming errors and the equations and models are correctly implemented. The method includes examination of modules of code, check on basic assumptions, and comparison between analytic results. A calculation is verified through a specific level of accuracy is demonstrated in the second model. The primary method to verify a calculation is the grid independent study [22] (Figure 2 and 3 ). 


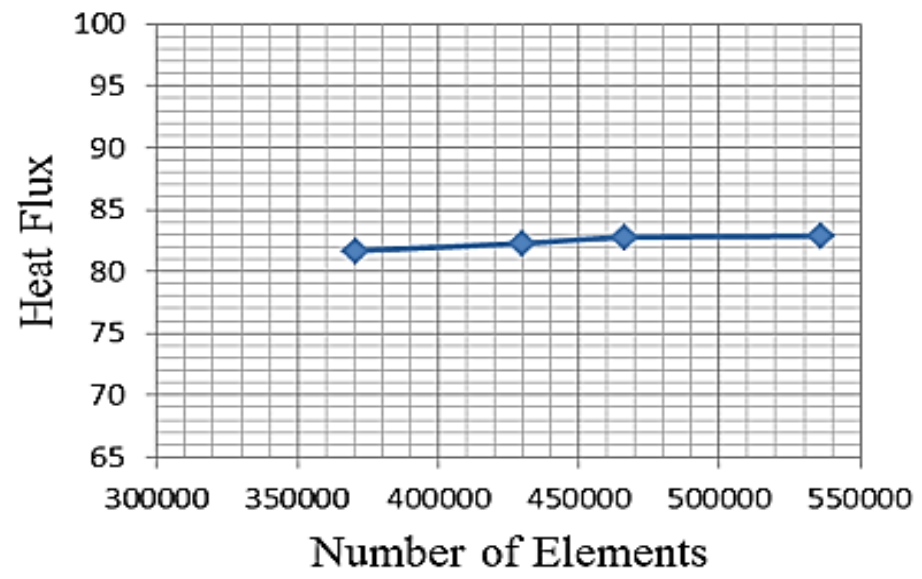

Figure 2. Variation of mean heat flux with various meshes.

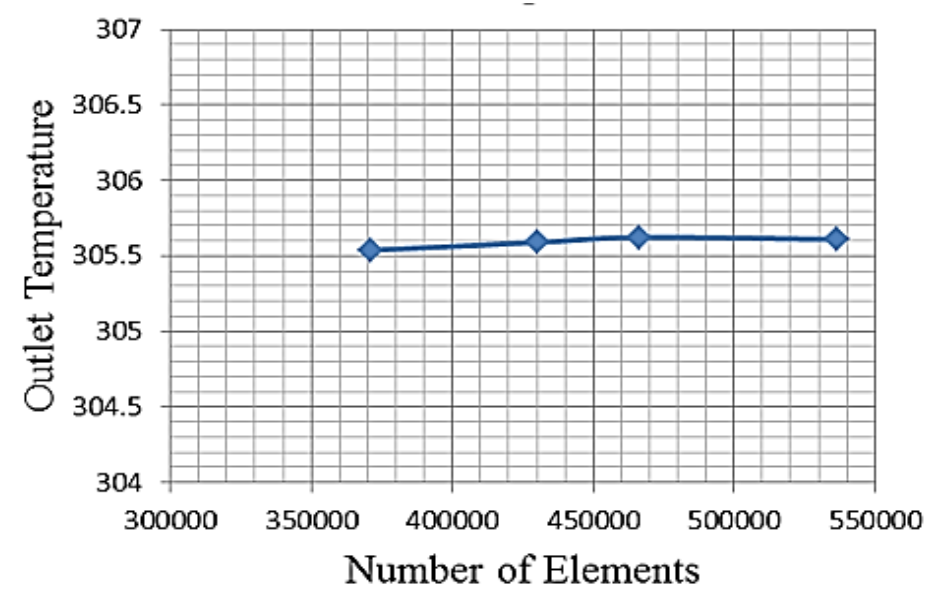

Figure 3. Variation of mean outlet temperature with various meshes.

With additional grid refinement, a grid-independent solution is present when the solution remains constant. For the last three mesh refining, Figures 2 and 3 have shown grid independence study results. On a computational model, a higher cell density after each solution convergence was used to create a new grid. The new as well as the prior mesh helped in obtaining the similar outcome. The process does not stop till it has achieved a grid independent solution. Therefore, less than one percent variation (1\%) between subsequent grid refinements to achieve grid independence is likely to be achieved by the computed mean heat transfer flux and mean outlet temperature. The grid independence study was performed for case 2 , where $\mathrm{L} / \mathrm{D}=1.5$.

The 3-D unstructured grid was generated by the Gambit grid generation; while, only half of the channel was considered for symmetry circumstances in span-wise direction. The test cases utilized two grids of different density for the computation process. A total of 360333 hexahedral cells were comprised with the coarse grid. A mesh distribution of $108 \times 52 \times 35$ was presented to fine-tune the mesh closer to the pins. At the interface, the mesh is non-conformal between coarse and fine region. The grid distribution for the coarse mesh was controlled effectively by mesh clustering toward the edges and walls in the wall function. There is significant impact of appropriate right turbulence model and near-wall treatments, considering the pressure drop and the heat transfer coefficient.

\section{Model Validation}

The CFD results were compared with experimental data of Summers [22]. Analysis of the heat transfer and pressure drop behavior was conducted on drop shaped pin fin. In this study, staggered array pin fin compact heat exchanger was characterized being places in a rectangular wide tunnel [22]. The study was based on airflow over a range of low Reynolds numbers in the laminar, low turbulent flow, and higher turbulent flow regimes.

Figures 4, 5, and 6 show friction coefficient, average heat transfer coefficient and Nusselt number curves, which presented the variation of them against Reynolds number. It was observed that the numerical results and the experimental data curves had typical trends. The primary points in the both curves had the same values but the deviation increased as Reynolds number increased. The results presented in this validation indicate that CFD may indeed provide a practical 
method of analyzing heat exchanger designs. Figures $4-6$ illustrated variation of non-dimensional pressure for each tapping diameter, with agreement up to approximately 500. These figures show the variation of non-dimensional pressure with Re number greater than 5 x 105. Decrease in Re number i.e. 180 x $103<\operatorname{ReD}<750$ x 103 relies on the universal curve. The shape of curves in these figures concerned with Re number is almost similar; however, increase in Re number is likely to lead to increased hole diameter at the same flow.

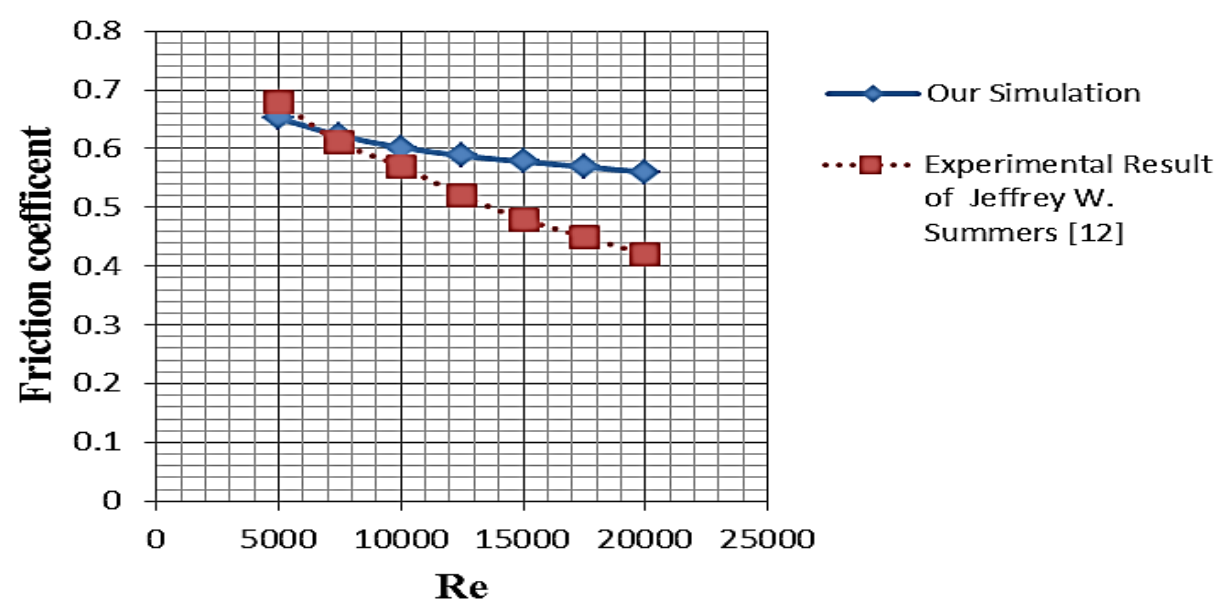

Figure 4. Friction coefficient variation against Reynolds number.

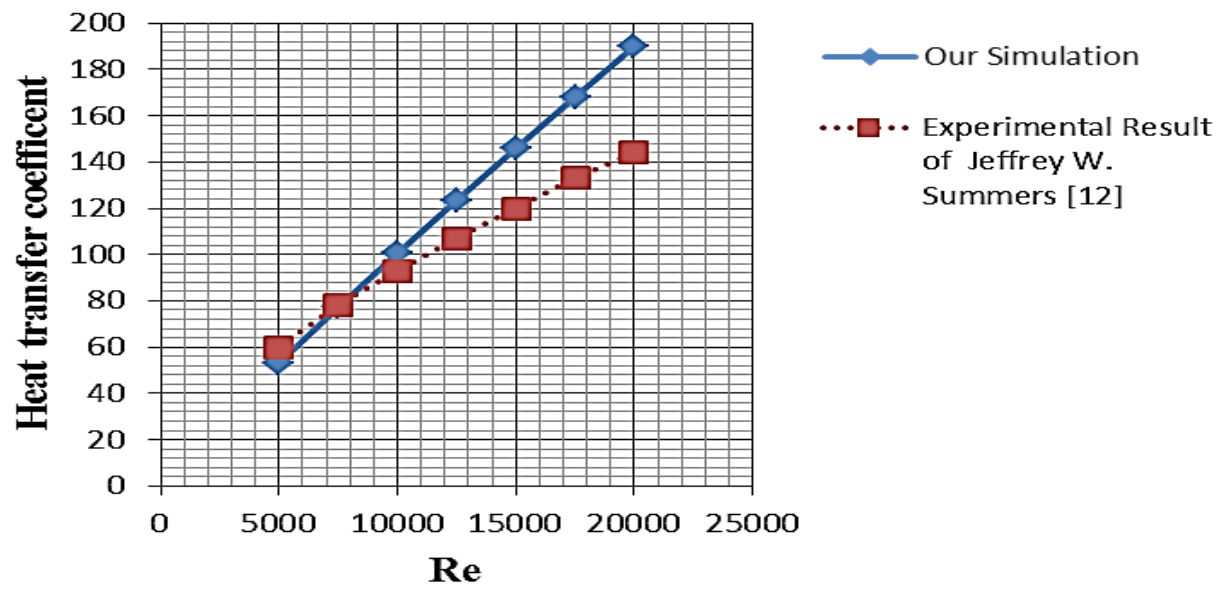

Figure 5. Heat transfer coefficient variation against Reynolds number. 

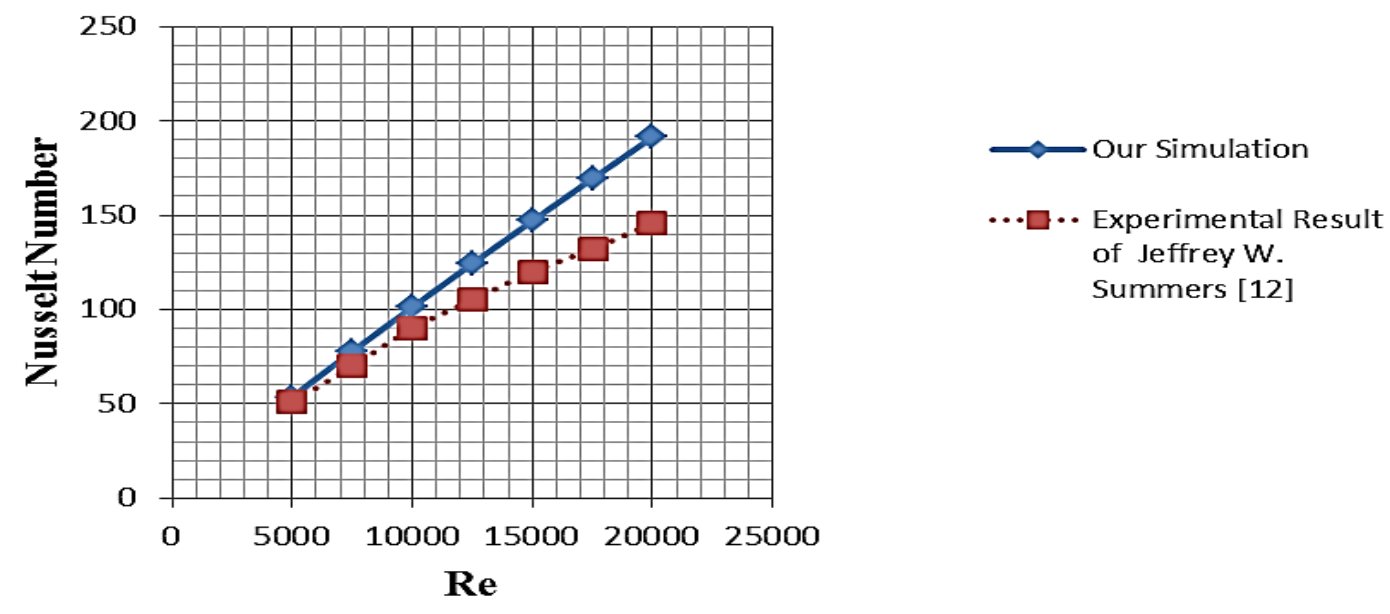

Figure 6. Nusselt number variation against Reynolds number.

\section{RESULTS AND DISCUSSIONS}

The present study has examined the heat transfer and loss pressure in a drop-shaped pin fin heat exchanger. For achieving the study objective, heat transfer coefficient was taken as the most critical parameter. The performance of a compact heat exchanger is evaluated using the 3-D numerical simulation. The simulation helps in the identification of best drop dimensions that can reduce the drop pressure and increase heat transfer across the heat exchanger by maintaining same heat transfer wetted surface area. Comparison of drops helped in evaluating the improvement in heat transfer and pressure drop.

The heat transfer wetted surface is the core foundation for the heat transfer coefficient. Moreover, bulk differential log mean temperature and system heat transfer rate flow are other important parameters. Figure 7 presents the average heat transfer coefficient versus the Reynolds number results for the different models in the turbulent flow region. The results show increase in the general average heat transfer coefficient with Reynolds number; while, heat transfer coefficient is not affected by the variations in the tail length of drop shaped pin fins because the heat transfer wetted area or surface wetted area remain constant for the four cases. This clearly shows that the aerodynamics of pin fin dies not affect the heat transfer coefficient.

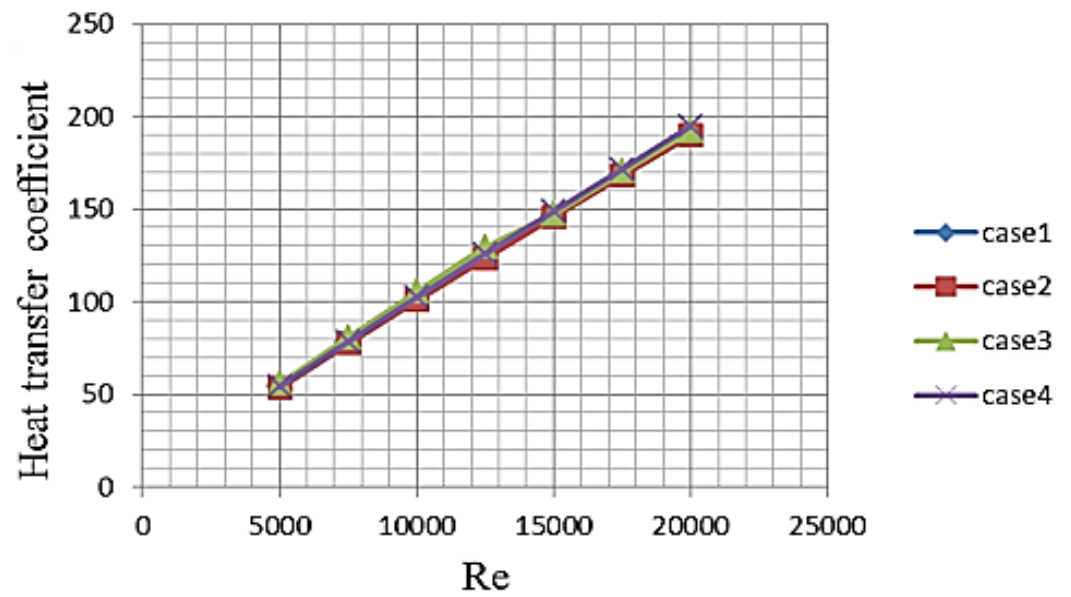

Figure 7. Heat transfer coefficient versus Reynolds number.

The Nusselt Number for a dimensionless temperature is expressed through the convective heat transfer. There is proportionality between heat transfer coefficient and hydraulic diameter and Nusselt number; whereas, there was inverse relationship of heat transfer coefficient and hydraulic diameter with the thermal conductivity. The variation in Nusselt number with the Reynolds number in the turbulent range is shown in Figure 8. The expected outcomes of heat transfer coefficient data are comparative to the Nusselt number that is associated to the heat transfer coefficient. The change in order is attributed to the increase in hydraulic diameter. From Figure 8, case 4 which has the greatest hydraulic diameter achieved the highest heat transfer performance and case 1 achieved the lowest one. 


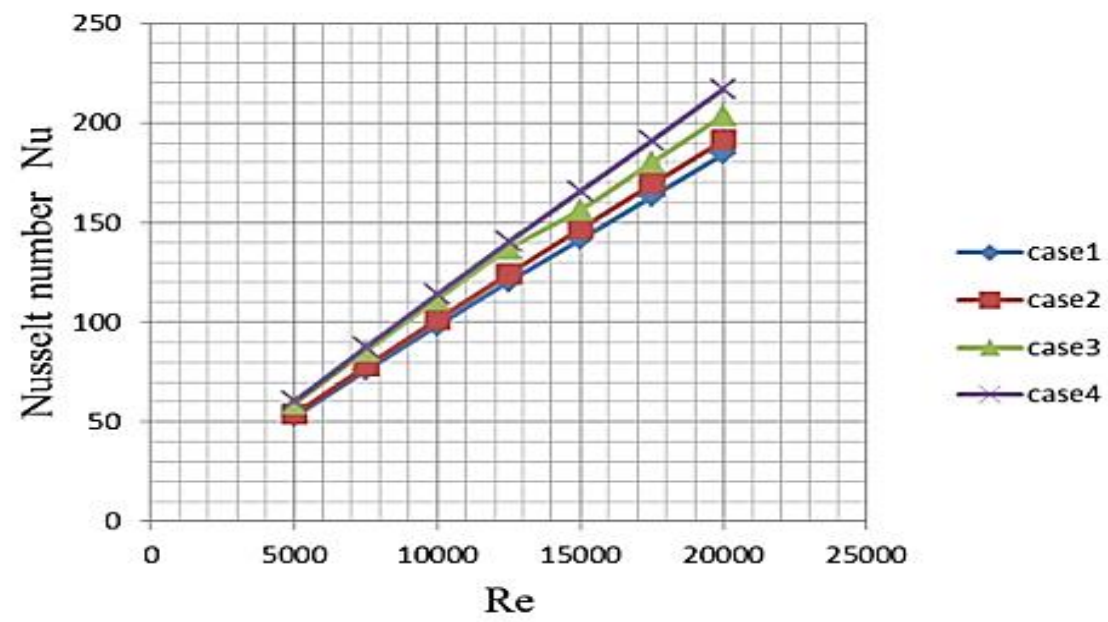

Figure 8. Nusselt number versus Reynolds number.

One of the important parameters is the friction factor as it indicates how much power is essential for achieving the heat transfer outcomes. There is direct proportionality between the CHE and the hydraulic diameter for the friction factor. From Figure 9 for case 3 the friction coefficient graph experiences a sudden jump at Reynolds number 15000 that could be attributed to the variation in the flow field (Figure 14 and 15). Figure 9 presents the results of friction factor versus Reynolds number in the turbulent region. The largest hydraulic diameter is the greatest friction factor because friction factor is directly proportional to the hydraulic diameter. Therefore, case 4 has the highest friction factor curve; while, case 1 has the lowest one. Other reason to increasing pressure losses is boundary layer separation.

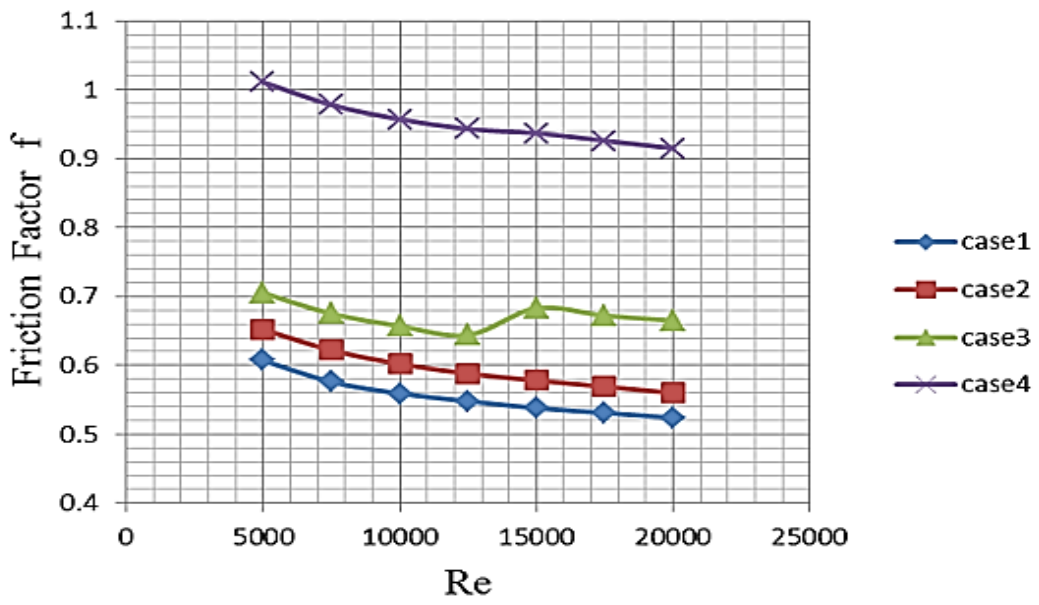

Figure 9. Friction coefficient versus Reynolds Numbers.

The flow was forced to reattach after separation because of the drops overlapping, so that it cannot be clear except in the last row and enlargement for domain end was needed. Taking Reynolds number equal to 5000 as a sample, the drop shaped tail length was affected since the model has the longest pins tail forces separation to delay (Figure 10, 11, 12, and 13). However, if the fins tail is shorter separation will occur early. 


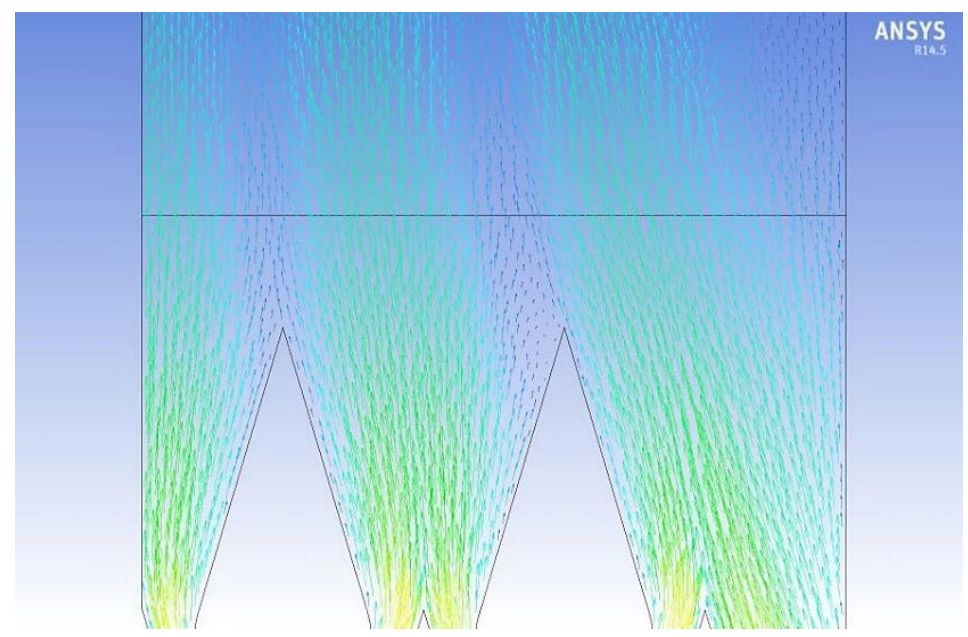

Figure 10. Velocity vectors of the last Row in case1(L/D=175) at Reynolds number 5000.

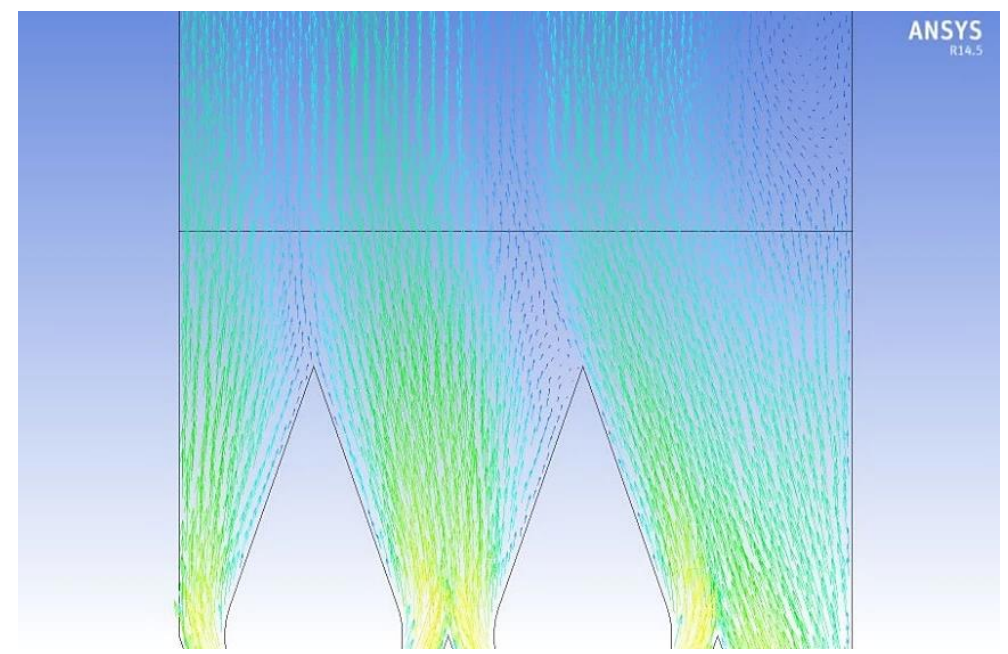

Figure 11. Velocity vectors of the last row in case $2(\mathrm{~L} / \mathrm{D}=15)$ at Reynolds number 5000.

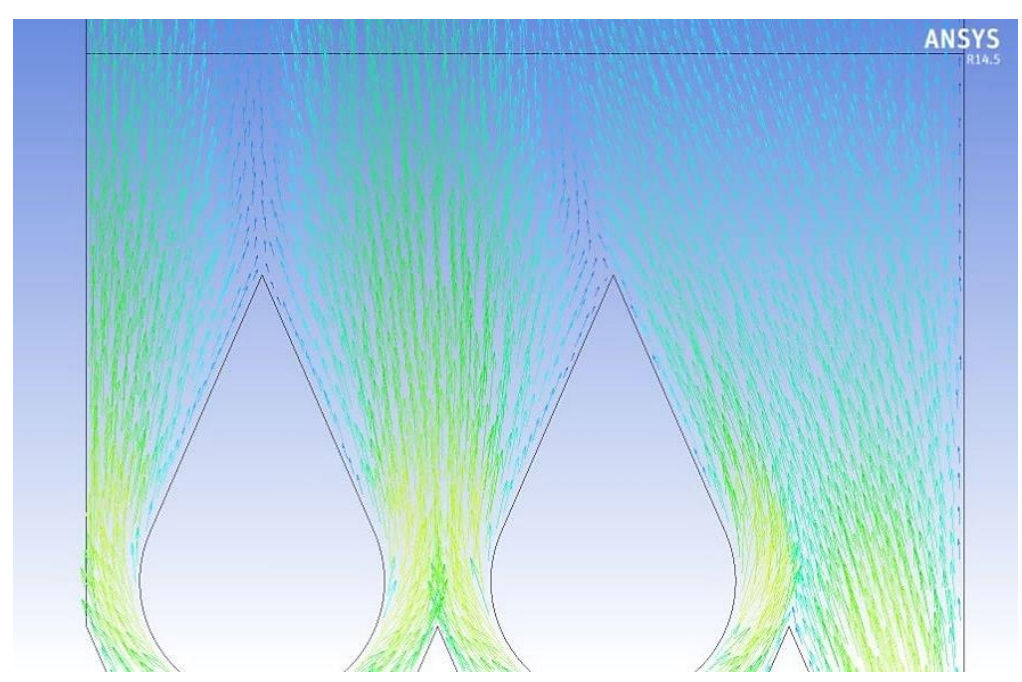

Figure 12. Velocity vectors of the last row in case $3(\mathrm{~L} / \mathrm{D}=125)$ at Reynolds number 5000. 


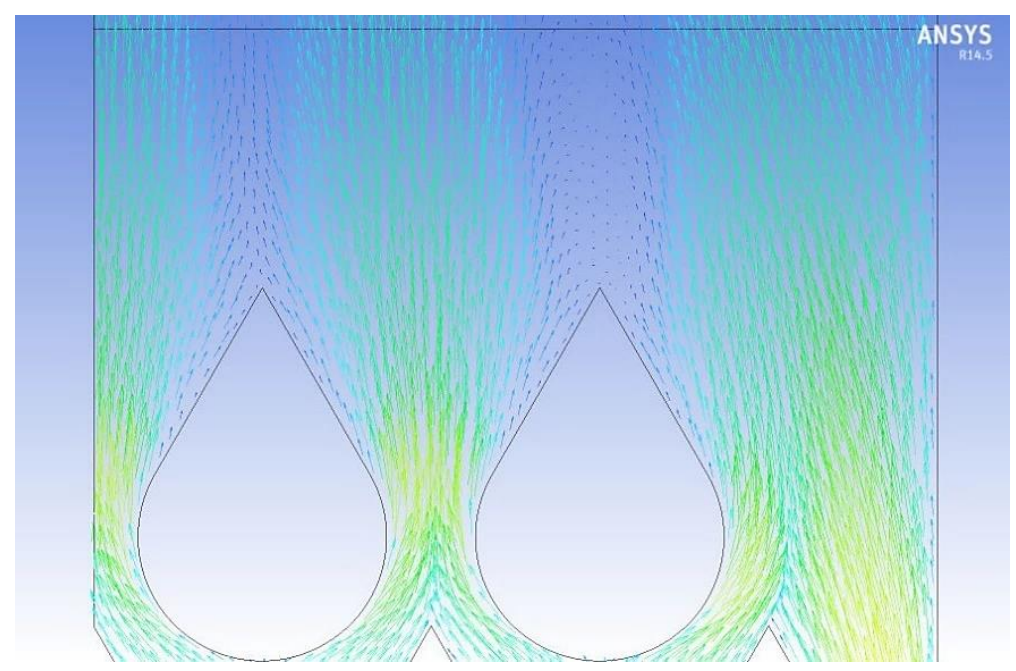

Figure 13. Velocity vectors of the last row in case4 $(\mathrm{L} / \mathrm{D}=1)$ at Reynolds number 5000.

Figure $10-13$ illustrate the velocity vectors of the last Row in case1 (L/D=175), case2 ( $\mathrm{L} / \mathrm{D}=15)$, case3 $(\mathrm{L} / \mathrm{D}=125)$, and case $4(\mathrm{~L} / \mathrm{D}=1)$ at Reynolds number 5000 , respectively. It clearly shows that case 4 indicates a clear vortex in addition to flow separation and this resulting in abnormal increasing to friction coefficient comparing to other models (Figure 14 and 15).

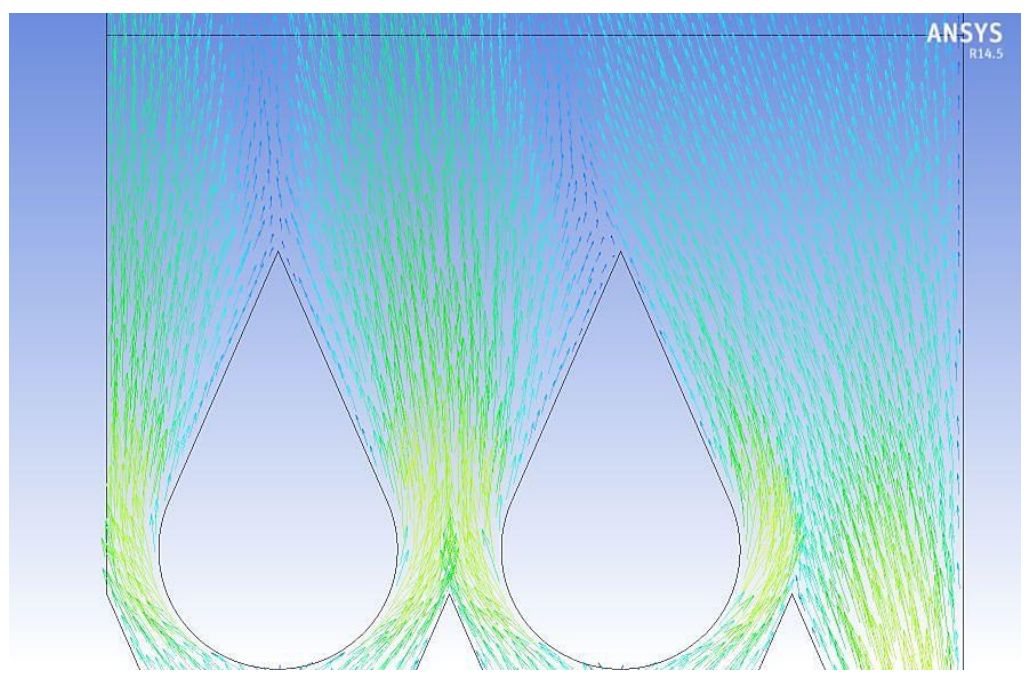

Figure 14. Velocity vectors for case 3 at Reynolds number 12500.

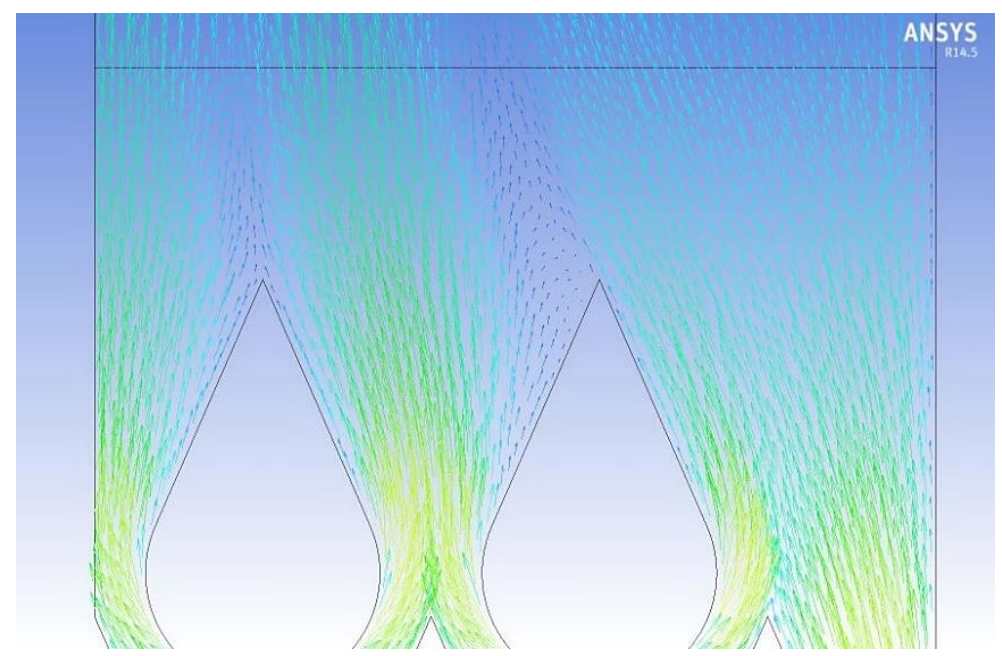

Figure 15. Velocity vectors for case 3 at Reynolds number 15000. 
Figures 16, 17, 18, and 19 have shown the velocity vector for different cases at Reynolds number 5000 as a sample. The loss of pin overlapping can be seen from the figures leading to more power consumption to accelerate air flow. The maximum working fluid velocity can be achieved across heat exchanger gained by case 1 due to the great pin overlapping. The observation that the maximum working fluid velocity across the heat exchanger decreased with decreasing of the ratio $\mathrm{L} / \mathrm{D}$.

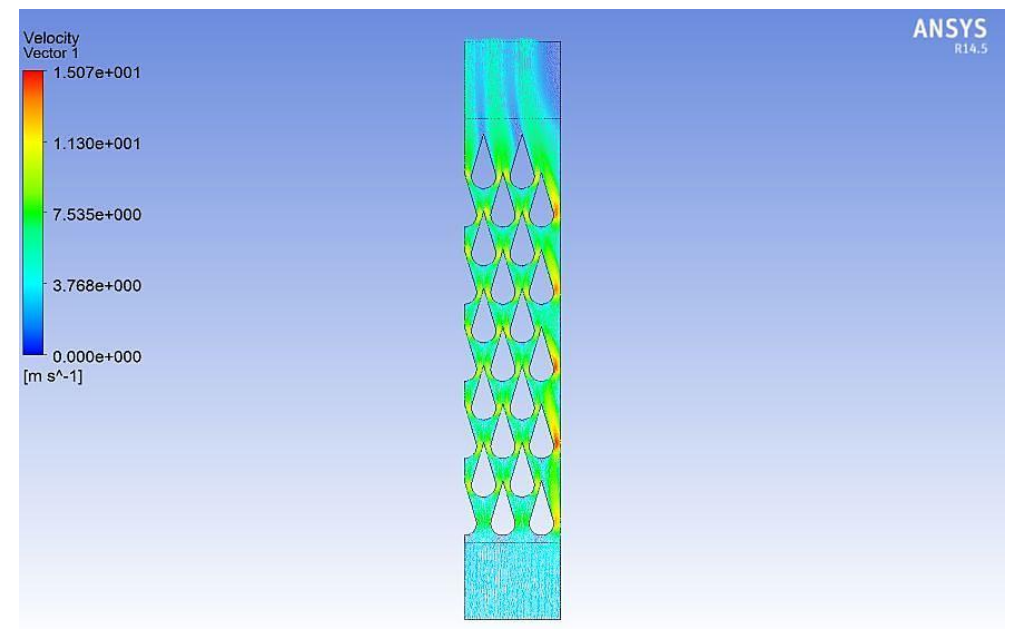

Figure 16. Velocity vectors for case 1 at Reynolds number 5000.

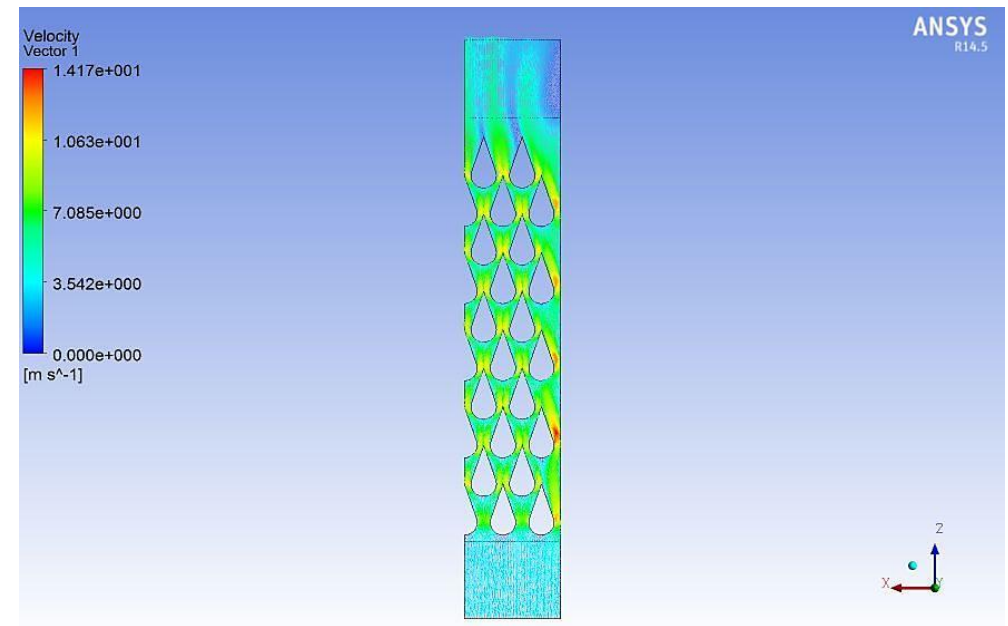

Figure 17. Velocity vectors for case 2 at Reynolds number 5000.

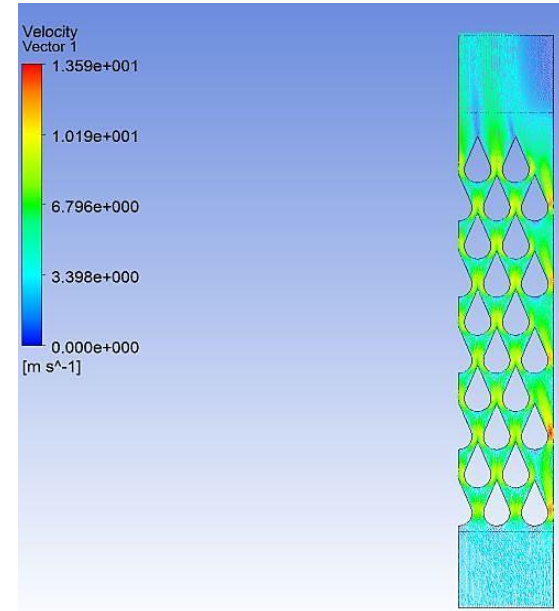

Figure 18. Velocity vectors for case 3 at Reynolds number 5000. 


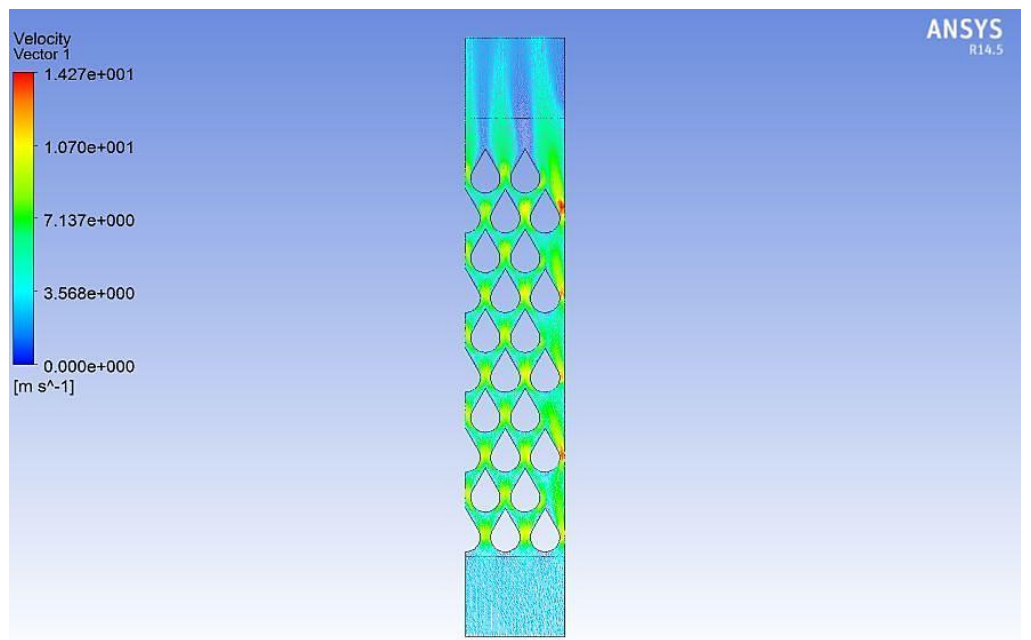

Figure 19. Velocity vectors for case 4 at Reynolds number 5000.

Figures 20, 21, 22, and 23 have shown temperature contour for different cases at Reynolds number 5000 as a sample. The results indicated that the maximum outlet temperature belonged to case 4 and that could be attributed to the air velocity across the heat exchanger. Since air velocity in case 4 was the slowest one which means air spent a long time in heat exchanger compared to the other cases to be hotter.

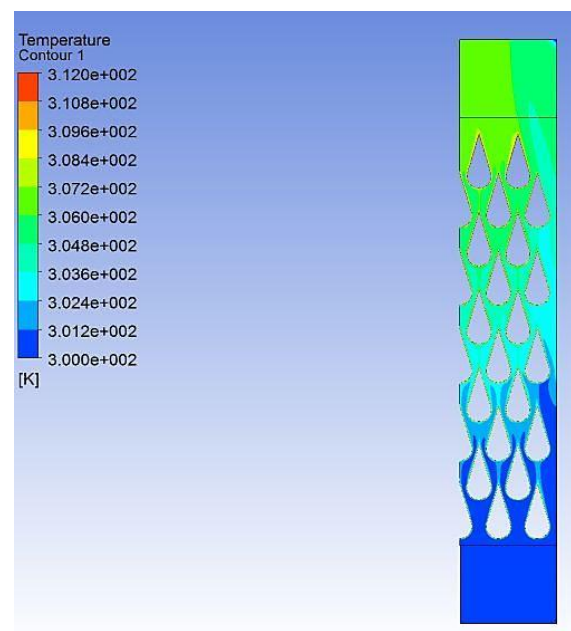

Figure 20. Temperature contour for case 1 at Reynolds number 5000.

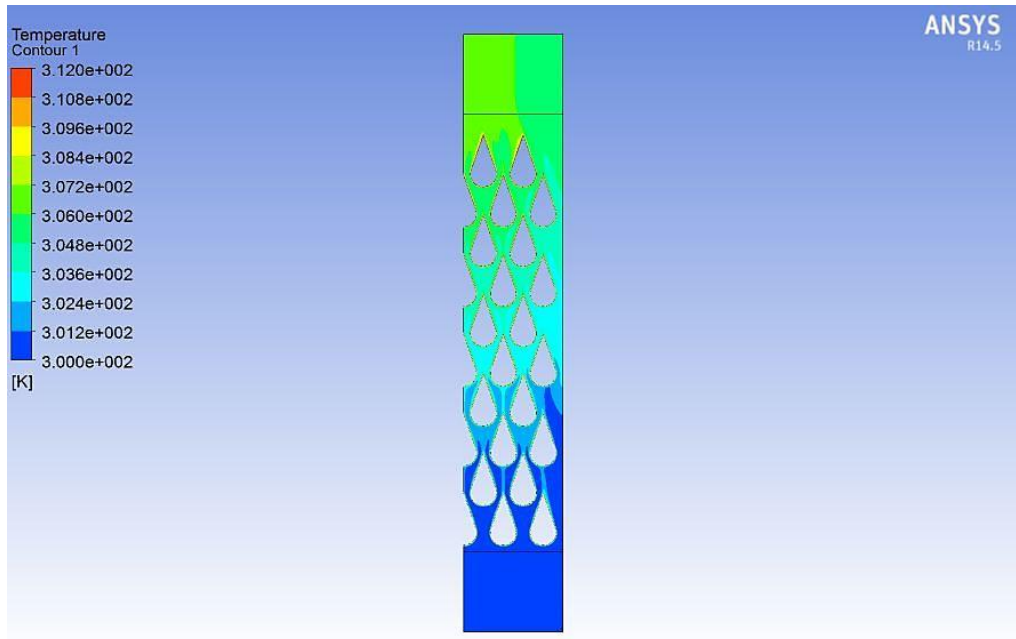

Figure 21. Temperature contour for case 2 at Reynolds number 5000. 


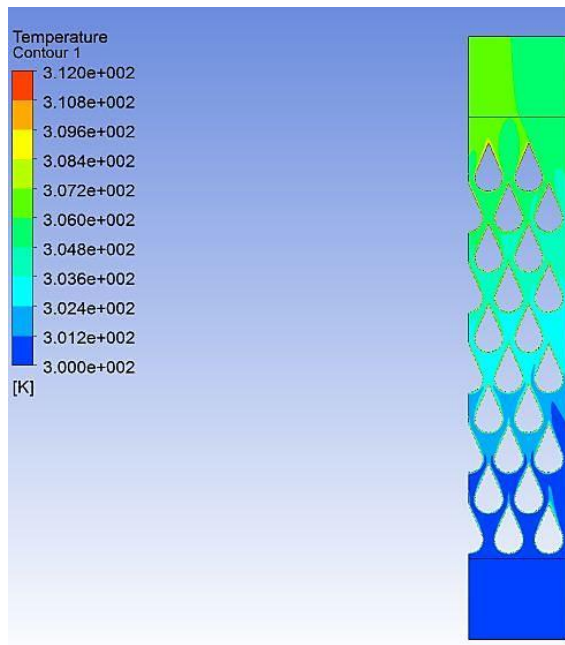

Figure 22. Temperature contour for case 3 at Reynolds number 5000.

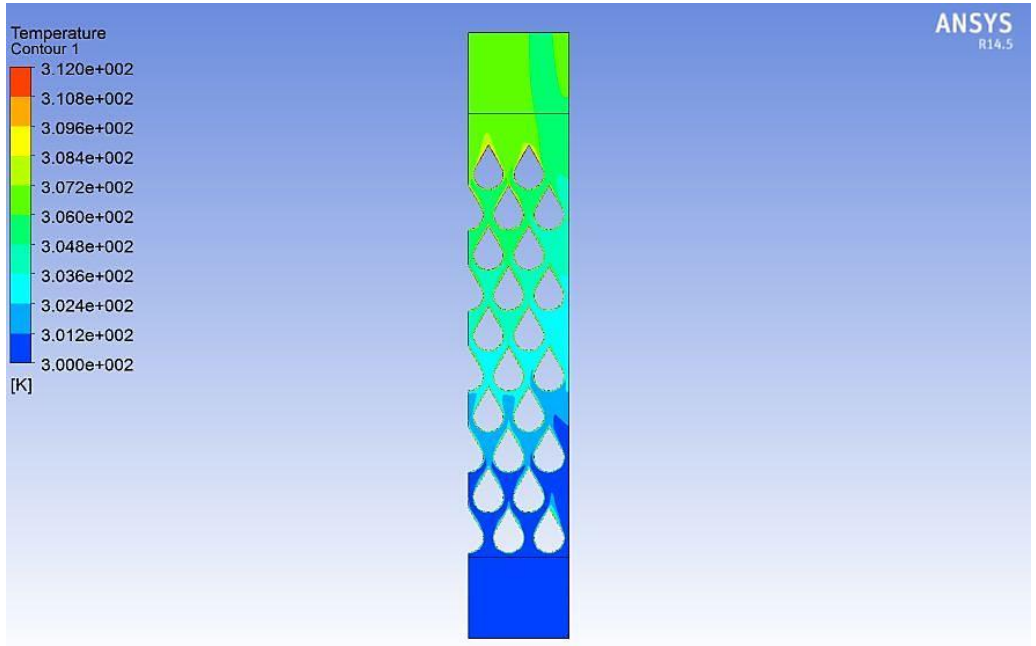

Figure 23. Temperature contour for case 4 at Reynolds number 5000.

\section{CONCLUSION}

The numerical results for the four cases L/D 1, 1.25, 1.5 and 1.75 indicated that the variations in pin tail length was not highly affected by heat transfer, but it affected frictional losses or pressure drop. The numerical results further indicated that the highest friction coefficient curve was belonged to the shortest pin tail length fins and the lowest friction coefficient curve was belonged to the tallest pin tail length fins. In other words, as there is an increase in the pin tail length, there is significant decrease in the frictional loss. The highest Nusselt's number carve belonged to the shortest pin tail length fins, and the lowest Nusselt's number carve belonged to the tallest pin tail length fins. Therefore, the optimum pin fin dimension was achieved in case $1, \mathrm{~L} / \mathrm{D}=1.75$, because it achieved the minimum frictional losses for the same heat transfer coefficient.

The overall performance of drop shaped pin fin heat exchanger increases by $27 \%$ after introducing perforations. This performance is likely to improve by increasing the numbers of perforations in the drop shaped pin fin. A higher heat transfer is provided by the pin fins drop, unlike the round pins for similar friction power. As compared to the round pins, the pin fins drop showed substantial decrease in the friction power. Moreover, the Reynolds number ranging between 3000 - 20000 has been confirmed by the present study. The numerical friction factor and ANSYS deems to overestimate the friction factor as compared to the experimental friction factor. The results depict that the ratio H/D has major effect on the wetted surface area that further affects the heat transfer rate along with the presence of unit cell analysis of the CHE. In this regard, the next step for future studies can be to investigate the impact of H/D. Moreover, future studies can show better performance as compared to round pins and drop pins by investigating other pin shapes for improving turbulent models. 


\section{ACKNOWLEDGEMENTS}

This publication was supported by the Deanship of Scientific Research at Prince Sattam bin Abdulaziz University, Alkharj, Saudi Arabia. The author is also very thankful to all the associated personnel in any reference that contributed in/for the purpose of this research.

\section{REFERENCES}

[1] F. Kreith, R. M. Manglik, and M. S. Bohn, Principles of heat transfer: Cengage learning, 2012.

[2] G. Pradeep and K. R. Narasimha, "Thermal performance of a vertical closed loop pulsating heat pipe and analysis using dimensionless numbers," Journal of Mechanical Engineering and Sciences, vol. 11, pp. 3240-3255, 2017.

[3] A. Abdullah, I. S. Mohamad, A. Y. Bani Hashim, N. Abdullah, B. W. Poh, M. H. Md Isa, et al., "Thermal conductivity and viscosity of deionised water and ethylene glycol-based nanofluids," Journal of Mechanical Engineering and Sciences (JMES), vol. 10, pp. 2249-2261, 2016.

[4] M. Haque, R. Bakar, K. Kadirgama, M. Noor, and M. Shakaib, "Performance of a domestic refrigerator using nanoparticlesbased polyolester oil lubricant," Journal of Mechanical Engineering and Sciences, vol. 10, pp. 1778-1791, 2016.

[5] M. Ma'arof, G. T. Chala, H. Husain, and M. S. Mohamed, "Influence of fins designs, geometries and conditions on the performance of a plate-fin heat exchanger-experimental perspective," Journal of Mechanical Engineering and Sciences, vol. 13, pp. 4368-4379, 2019.

[6] N. Sahiti, "Thermal and fluid dynamic performance of pin fin heat transfer surfaces," 2006.

[7] M. U. Kumar, M. M. Hussian, and M. Y. Ali, "Review of Heat Transfer Enhancement Techniques in Square Ducts with Inserts," International Journal of Emerging Technology and Advanced Engineering, vol. 3, pp. 767-770, 2013.

[8] R. K. Shah and D. P. Sekulic, Fundamentals of heat exchanger design: John Wiley \& Sons, 2003.

[9] A. S. Kushwaha and R. Kirar, "Comparative study of rectangular, trapezoidal and parabolic shaped finned heat sink," IOSR J. Mech. Civ. Eng, vol. 5, pp. 1-7, 2013.

[10] Y. Peles, A. Koşar, C. Mishra, C.-J. Kuo, and B. Schneider, "Forced convective heat transfer across a pin fin micro heat sink," International Journal of Heat and Mass Transfer, vol. 48, pp. 3615-3627, 2005.

[11] M. E. Lyall, A. A. Thrift, K. A. Thole, and A. Kohli, "Heat transfer from low aspect ratio pin fins," Journal of turbomachinery, vol. 133, 2011.

[12] H. Nabati, "Optimal pin fin heat exchanger surface," Mälardalen University, 2008.

[13] N. Sahiti, A. Lemouedda, D. Stojkovic, F. Durst, and E. Franz, "Performance comparison of pin fin in-duct flow arrays with various pin cross-sections," Applied Thermal Engineering, vol. 26, pp. 1176-1192, 2006.

[14] A. Dewan, P. Patro, I. Khan, and P. Mahanta, "The effect of fin spacing and material on the performance of a heat sink with circular pin fins," Proceedings of the Institution of Mechanical Engineers, Part A: Journal of Power and Energy, vol. 224, pp. 35-46, 2010.

[15] O. Bergelin, K. Bell, and M. Leighton, "Heat transfer and fluid friction during flow across banks of tubes. VII. Bypassing between tube bundle and shell," Chem. Eng. Progr., vol. 55, 1959.

[16] E. M. Sparrow and V. Grannis, "Pressure drop characteristics of heat exchangers consisting of arrays of diamond-shaped pin fins," International Journal of Heat and Mass Transfer, vol. 34, pp. 589-600, 1991.

[17] Y.-T. Yang and H.-S. Peng, "Numerical study of pin-fin heat sink with un-uniform fin height design," International Journal of Heat and Mass Transfer, vol. 51, pp. 4788-4796, 2008.

[18] M. A. Elyyan, A. Rozati, and D. K. Tafti, "Investigation of dimpled fins for heat transfer enhancement in compact heat exchangers," International Journal of Heat and Mass Transfer, vol. 51, pp. 2950-2966, 2008.

[19] O. Uzol and C. Camci, "Elliptical Pin Fins as an Alternative to Circular Pin Fins for Gas Turbine Blade Cooling Applications: Part 1-Endwall Heat Transfer and Total Pressure Loss Characteristics," in ASME Turbo Expo 2001: Power for Land, Sea, and Air, 2001.

[20] B. Moshfegh and R. Nyiredy, "Comparing RANS models for flow and thermal analysis of pin fin heat sinks," in Proc. 15th Australasian Fluid Mechanics Conference, 2004.

[21] K.-S. Yang, W.-H. Chu, Y. Chen, and C.-C. Wang, "A comparative study of the airside performance of heat sinks having pin fin configurations," International Journal of Heat and Mass Transfer, vol. 50, pp. 4661-4667, 2007.

[22] A. Dewan, L. Dayanand, and P. Patro, "Mathematical modeling and computation of threedimensional, turbulent, convective heat transfer in a heat exchanger with circular pin fins," App. Mathematical Modeling, pp. 273-296, 2008.

[23] J. Boulares, "Numerical and experimental study of the performance of a drop-shaped pin fin heat exchanger," NAVAL POSTGRADUATE SCHOOL MONTEREY CA DEPT OF MECHANICAL ENGINEERING2003.

[24] H. K. Versteeg and W. Malalasekera, An introduction to computational fluid dynamics: the finite volume method: Pearson education, 2007.

[25] J. W. Summers, "An empirical study of a pin fin heat exchanger in laminar and turbulent flow," Naval Postgraduate School Monterey CA2003. 
[26] T. Barth, R. Herbin, and M. Ohlberger, "Finite volume methods: foundation and analysis," Encyclopedia of Computational Mechanics Second Edition, pp. 1-60, 2018.

[27] P. A. Bamberger, M. Biron, and I. Meshoulam, Human resource strategy: Formulation, implementation, and impact: Routledge, 2014.

[28] S. Dimas, "A CFD analysis of the performance of pin-fin laminar flow micro/meso scale heat exchangers," Naval Postgraduate School Monterey CA2005.

[29] W. Oberkampf and T. Trucano, "Validation methodology in computational fluid dynamics," in Fluids 2000 Conference and Exhibit, 2000, p. 2549. 